\title{
Impacts of Various Parameters on Transit Signal Priority Effectiveness
}

\author{
Vikki Ngan, IBI Group \\ Tarek Sayed, University of British Columbia \\ Akmal Abdelfatah, American University of Sharjah
}

\begin{abstract}
This research examines the impacts of a number of traffic parameters on the effectiveness of a Transit Signal Priority (TSP) application. TSP is tested with the $98 \mathrm{~B}$-line rapid buses along Granville Street in the City of Vancouver as a case study. VISSIM, a micro-simulation software (PTV 2002), is used to simulate TSP operation on the corridor. The traffic parameters studied include: bus approach volume, cross street volume/capacity ( $\mathrm{v} / \mathrm{c}$ ) ratio, bus headway, bus stop location, bus check-in detector location, left turn condition, and signal coordination. Based on results from these experiments, recommendations are provided for TSP application on Granville Street. In general, it is found that a TSP application would be most effective under a traffic condition that has moderate-to-heavy bus approach volume, little or no turning volume hindering bus movement, slight-to-moderate cross street $v / c$ ratio, farside bus stop, and signal coordination for traffic running in the peak direction.
\end{abstract}




\section{Introduction}

Transit Signal Priority (TSP) is an Intelligent Transportation System (ITS) measure that modifies the normal signal operation process to better accommodate transit vehicles. It aims to reduce the delay and travel time of transit vehicles, thereby increasing the quality of a transit service; meanwhile, it attempts to provide these benefits with minimal impact on other road users and cross street traffic in particular. TSP has been widely tested and deployed around the world, especially in the United States and Europe, as a tool to improve transit performance. However, previous research has shown that the impacts and effectiveness of a TSP application is subjective and depends on its surrounding traffic environment (such as signal timing settings, congestion levels, etc.). Consequently, it is important to study the influences of various traffic and transit parameters on the impacts and effectiveness of a TSP application.

This research studied the effects of seven traffic and transit parameters on the effectiveness of TSP. These parameters include: bus approach volume, cross street volume/capacity ( $\mathrm{v} / \mathrm{c}$ ) ratio, bus headway, bus stop location, bus check-in detector location, left turn condition, and signal coordination. The $98 \mathrm{~B}$-Line bus route, along the Granville Street corridor, Vancouver, British Columbia, is used as a case study. Based on the results, some generic guidelines and recommendations for TSP applications are proposed.

\section{Previous Work}

Several studies investigated the relationship between the effectiveness of a TSP application and the surrounding traffic environment. The studied traffic parameters can be categorized into four main areas: vehicular volume, bus headway, bus stop locations, and signal coordination.

Garrow and Machemehl (1998) used CORSIM to simulate several green extension measures on the Gaudalupe corridor in Austin, Texas. They reported that there would be a severe negative impact on the cross-street traffic if the cross-street saturation level is above 1.0 with a 10 -second green extension, or if the cross-street saturation level is above 0.9 with a 20 -second green extension. Under these conditions, they reported that the cross-street traffic would require 2 to 3 cycles to recover. Balke, Dudek and Urbanik (2000) examined the impacts of a proposed "intelligent bus priority concept" on the bus and general traffic performance at bus approach $v / c$ ratios of $0.50,0.80$ and 0.95 . Their results illustrated that the intelli- 
gent priority system could improve bus travel time by more than $25 \%$ at three bus approach $\mathrm{v} / \mathrm{c}$ ratios; meanwhile, it slightly reduced the travel time of general traffic running on or opposite to the bus approach. However, Balke, Dudek and Urbanik also reported that the proposed system would have a substantial negative impact on the average stop delay of traffic traveling on the non-priority approaches with $\mathrm{v} / \mathrm{c}$ levels greater than 0.95 .

Little work had addressed the question of optimal bus headway for TSP operations. Khasnabis and Rudraraju (1997) examined the possible consequences of different headways on a TSP operation. A major bus route in Ann Arbor, Michigan was selected for demonstration and was simulated using NETSIM. Route-level analysis illustrated that a 10-minute headway would produce the highest effectiveness in reducing delay of the target direction and both directions of the main street. They also reported that if a reduction in the delay of the cross street or the combined main street and cross street was the objective, a 7.5-minute headway would be considered as the best alternative. Agrawal, Waller and Ziliaskopoulos (2002) examined the impact of bus frequency on a TSP application. From a 30-minute simulation, they reported the following observations on the impact of bus frequency:

- Total system travel times of "no preemption" strategy and "preemption" strategy converge when the number of buses rises above 30 per 30 minutes.

- The least difference in total system travel times with and without preemption was observed at a bus frequency of 15 per 30 minutes or 2-minute headway. The authors claimed that the difference did not remain constant at a higher bus frequency because of the vehicle route changing that occurred after preemptions.

- The benefit from preemption on bus trip time increased when there were fewer buses; above approximately 20 buses per 30 minutes, the benefit decreased and leveled off.

With regard to bus stop location, there was a clear preference for the use of farside bus stops for the implementation of active TSP, for which real-time detections of buses are required. This is because the uncertain passenger loading and unloading time at a near-side bus stop would increase the uncertainty in predicting arrival time of a bus at an intersection (Daniel 1997). It was also believed that a far-side 
bus stop could maximize the efficiency of a signal priority operation, as there would be less influence from the dwell time at the bus stop (Huffman, et al. 1998).

Several studies investigated the effect of incorporating transit signal priority into a coordinated network. Skabardonis (2000) proposed that transit signal priority should only be granted if there is sufficient spare green time in a signal cycle. This would mean that little or no transit vehicles would be given priority along a congested corridor or during the peak hours. According to Skabardonis (2000), the spare green time was computed as:

$$
G_{\text {Spare }}=\sum_{i=1}^{N} G_{i} *\left(1-X_{i}\right)
$$

where

$$
\begin{aligned}
& \mathrm{Gi}=\text { green time for phase } \mathrm{i}, \\
& \mathrm{Xi}=\text { degree of saturation of the critical link in phase } \mathrm{i} \text {, and } \\
& \mathrm{N}=\text { total number of phases in a cycle. }
\end{aligned}
$$

Chatila and Swenson (2001) proposed to set the maximum green extension time to $20 \%$ (or one-fifth) of the cycle length. To return to coordination, every 5 th second in the cycle is skipped until the local clock (with adjusted time for green extension) and the master clock (with original reference time) are back in synchronization. Whereas, Duerr (2000) attempted to use a sophisticated algorithm called DARVIN (with static optimization by Genetic Algorithm and dynamic adaptation by Neural Network) to minimize the interference between public transit vehicles and other vehicles and to maintain the existing signal coordination as much as possible.

\section{Methodology}

As described earlier, the main objective of this article is to investigate the impact of various traffic and transit parameters on the effectiveness of TSP. To achieve this, Transit Signal Priority (TSP) application of the $98 \mathrm{~B}$-line rapid transit buses along Granville Street in the City of Vancouver is used as a case study and is simulated by VISSIM. 


\section{Experiment Site}

The Granville Street corridor, where the 98 B-Line buses run, is one of the busiest traffic and transit corridors in the Greater Vancouver Regional District (GVRD). The studied section along the Granville Street corridor stretches approximately $6 \mathrm{~km}$, from Broadway to 70th Avenue. All traffic data are based on morning peak period data of year 2000. Granville Street morning peak hour entering volumes are around 2,000 vehicles per hour (Veh/hr) and 1,000 Veh/hr in the northbound and southbound directions, respectively. The $98 \mathrm{~B}$-Line buses operate in mixed traffic at 10-minute headways during the morning peak period. There are 19 signalized intersections along the section.

The B-Line bus check-in detectors are located approximately 100 meters from the intersection stop bars for real-time detection of the buses. Five on-street bus stops for the 98 B-Line are placed on each Granville Street approach. Most of them are on the farside (i.e., downstream) of the intersections, except the northbound bus stop at the intersection of Granville Street and Broadway where a nearside bus stop is placed because of a high transit stop demand that already exists on the farside of the intersection. The TSP strategies experimented in this study are:

(i) Green extension: Extension of the green time when a bus checks in during the bus-approach green phase and cannot check out before the original green phase elapsed. The green phase for the bus would be extended until either the bus checks out or when the maximum green extension of 14 seconds is reached, whichever comes first. Beyond the 14-second green extension, the green phase of the bus-approach phase would end. To maintain coordination, the cross street green time reduces accordingly after a green extension call.

(ii) Red truncation (or Early Green): The green time of the cross street phases would be truncated (or shortened) when a bus checks in during the busapproach red phase, subjected to the required flash don't walk (FDW) time and a 3 -second minimum walk time of the pedestrian phase (conflicting to the TSP-eligible bus approaches); and

(iii) Restriction of TSP calls in two successive cycles. 


\section{VISSIM Simulation and Calibration}

VISSIM, a micro-simulation software, is used to simulate TSP operation on the Granville Street corridor. VISSIM has a number of features that make it a useful tool for modeling transit operation and transit priority:

1. VISSIM allows the development of user-defined signal logics to test different TSP strategies. The user-defined signal logics are coded with VAP, a Clike programming language that offers traffic-related functions such as detector calls, switching of signal phases, and transit phasing (PTV 2002)

2. VISSIM allows the assignment of detailed priority rules to model yielding movements at signalized and non-signalized intersections.

3. VISSIM has a wide range of user-customizable output files for measures-ofeffectiveness such as volume, mean speed, travel times, delay, queue lengths, and number of stops. Detailed signal records can also be logged.

As with every modeling exercise, a calibration process of the base network is performed. A geometric network calibration is performed by looking at the VISSIM graphical user interface for any unusual behavior of the traffic, which may be due to inexact coding of the network construction or traffic signal logics. Additionally, the model is calibrated to isolate unrelated traffic factors, which could influence the impact of the studied traffic parameters.

The VISSIM network was compared with the real-life network. The existing geometric conditions, actual input volumes, and actual signal timings on the Granville Street corridor were used as the base of the model.

\section{VISSIM Modeling}

After calibration, a traffic simulation model, named "NoTAC," is developed as the base model (with no TSP) of the 98 B-Line buses on Granville Street.

Since the goal of this article is to investigate the individual impact of traffic parameters on TSP effectiveness, the NoTAC model assumes No Turning to and from Granville Street, no Actuation from pedestrians at the pedestrian signals (or half signals), and no turning from the Cross Streets. Two-phase fixed time signals are tested along the corridor. In addition, it neglects actual gradient of the corridor, actual exclusive HOV and bus lanes, and actual on-street parking on Granville Street during the morning peak hours. These assumptions create a hypothetical case that eliminates factors that might affect performance, and is used as a base for comparison and for evaluating one traffic variable at a time. 
Total simulation time is 1 hour and 15 minutes, including a normalization period of 15 minutes at the beginning to fill the network with vehicles, and a simulation period of 1 hour to collect data for analyses. Each experiment is performed with five different random seeds to account for the stochastic traffic input. This is required to ensure the validity and stability of the results.

Results from the five simulation runs are averaged using a "Trimmed Average" approach, which excludes the highest and the lowest results of the runs, then averaging the remaining. This aims to reduce the effect of randomness in the simulation results. The trim-averaged simulation results are used to test the sensitivities of TSP impacts or effectiveness to the studied parameters.

\section{Evaluation}

Two measures of effectiveness (MOEs) used in the evaluations are the impact of TSP and the green extension success rate. The impact of TSP compares the B-Line bus and/or cross street performance (i.e., travel time or delay) with and without TSP implementation; and the green extension success rate measures the rate at which a bus might clear the intersection successfully with a green extension. Additionally, results of the simulations are presented in one of the two levels of aggregation: corridor-level presents the traffic performance along the Granville Street corridor, and approach-level focuses on the traffic performance on an approach to an intersection.

\section{Bus Approach Volume (Corridor-Level)}

The B-Line buses operate at a default headway of 10 minutes and the Granville Street (or bus approach) volumes considered for this experiment are 500, 1,000, 1,500, 2,000, 2,500, and 2,700 veh/hr/3-lanes. These Granville Street volumes represent average $\mathrm{v} / \mathrm{c}$ ratios from 0.2 to 1.0 (i.e., at capacity). The $\mathrm{v} / \mathrm{c}$ ratio for the corridor is calculated based on the generated volume and capacity value, which is estimated using the average green times of all signalized intersections along the corridor. The Highway Capacity Manual Model procedure is used for the calculation of the $\mathrm{v} / \mathrm{c}$ ratio. When considering a change in $\mathrm{v} / \mathrm{c}$ ratio and fixing all other factors, as summarized in Figure 1, the following remarks can be made: 
Figure 1. (a) Impact on Bus Travel Time

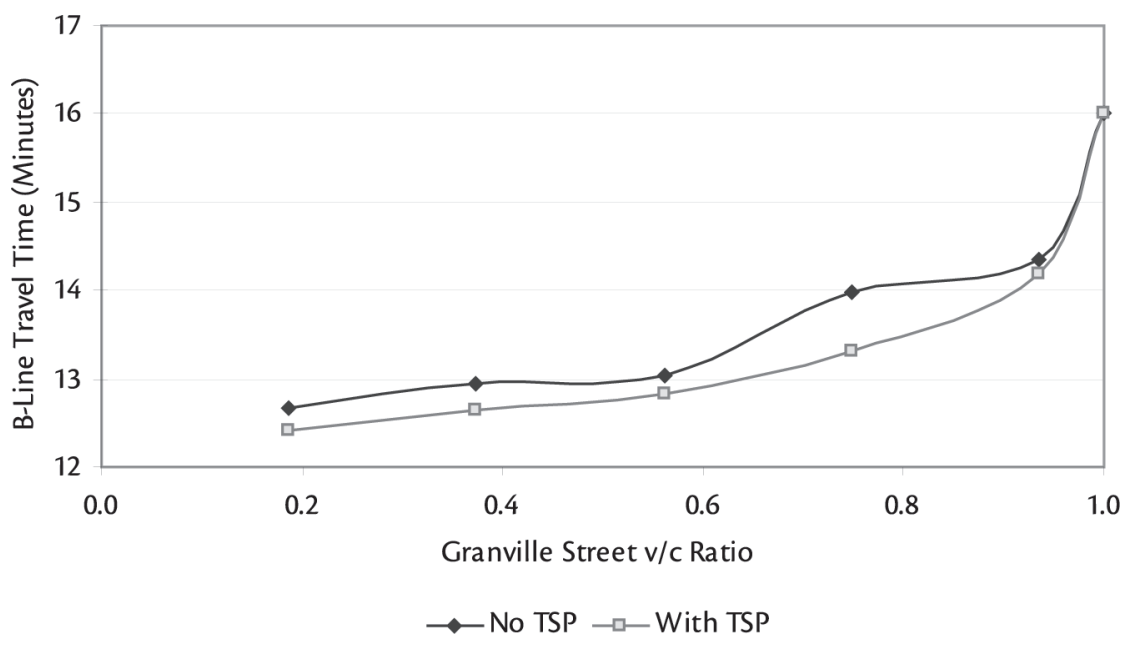

Figure 1. (b) Impact on Green Extension Success Rate

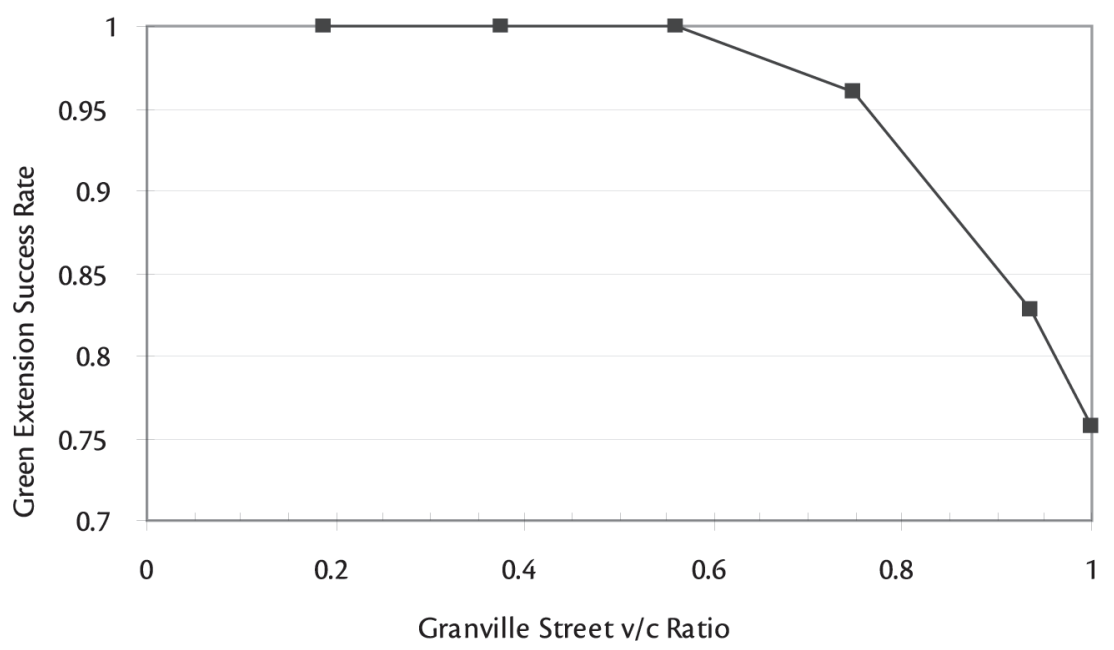


- TSP application would be most effective under moderate-to-heavy traffic condition. TSP's improvement on the B-Line bus performance decreases at low bus approach $\mathrm{v} / \mathrm{c}$ ratios, at which the buses would not encounter too much traffic delay. The improvement also decreases as the traffic condition approaches capacity, because congestion would hinder bus movement.

- The green extension success rate would be reduced as bus approach volume increases. The reduction in green extension success rate could be attributed to an increasing traffic volume on Granville Street, which lengthens the time required by the buses to enter the intersection after checking in, making the buses less likely to clear the intersection during the green extension phase.

\section{Cross Street Volume/Capacity Ratio (Approach-Level)}

This experiment examines the impact of TSP on cross street delay for various cross street $\mathrm{v} / \mathrm{c}$ ratios. The result shows that the impact of TSP on cross street performance is minimal at low cross street $\mathrm{v} / \mathrm{c}$ ratios. Whereas, TSP has a moderate impact on cross street performance at cross streets with a $\mathrm{v} / \mathrm{c}$ ratio above 0.8 , it has a significant impact on cross street performance (i.e., causes high cross street delay and increases delay recovery cycles) at cross streets with $\mathrm{v} / \mathrm{c}$ ratios above 0.9. Figure 2 shows the simulated cross street delay trends with and without TSP application under the approach $\mathrm{v} / \mathrm{c}$ ratios of $0.8,0.9$, and 1.0 . The $\mathrm{v} / \mathrm{c}$ ratios are obtained using the procedure described in the previous section. The numerical value on top of each vertical line represents the duration of green extension (solid line) or red truncation (dotted line) conferred to the B-Line bus approach, which is the difference between the actual green time and the maximum green time of the fixed time signal phases. The circle identifies the maximum number of recovery cycles required for each cross street $\mathrm{v} / \mathrm{c}$ ratio scenario.

\section{Bus Headway (Corridor-Level)}

The B-Line bus travel time along the Granville Street corridor is also assessed under five headway scenarios, with and without the allowance of TSP calls in successive cycles. Figure 3 shows the improvement in bus travel time under different headways when TSP is implemented.

Based on the results of this analysis, 10 minutes is the optimal bus headway at which TSP brings the highest improvement (or reduction) in bus travel time. At headways greater than the optimal headway (i.e., $>10$ minutes), fewer TSP requests limit the benefits of TSP on the B-Line bus performance. Whereas, at headways smaller than the optimal headway (i.e., $<10$ minutes), the improvement of TSP on 
Figure 2. Average Cross Street Cycle Delay (with and without TSP) at:

(a) $\mathrm{v} / \mathrm{c}$ Ratio $=\mathbf{0 . 8}$

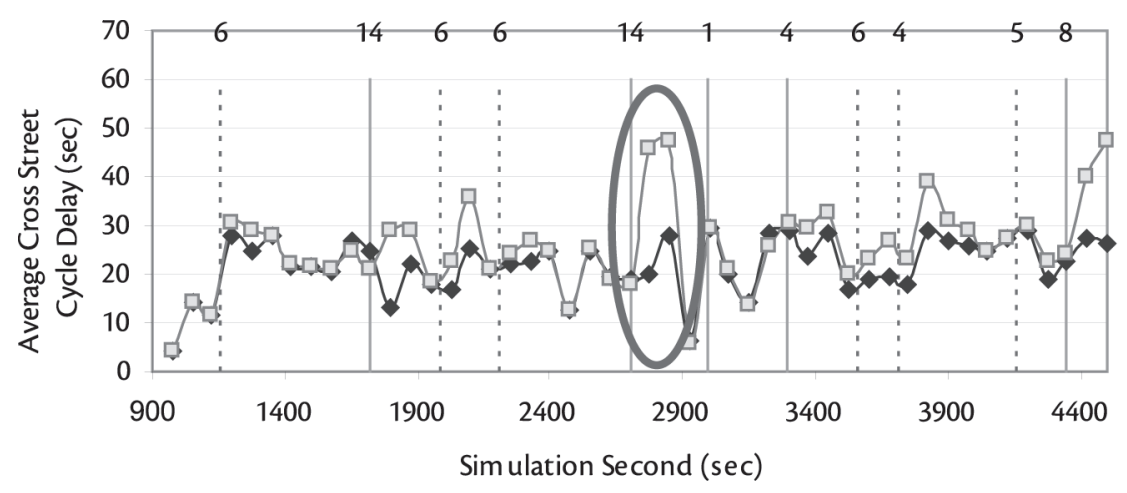

$\longrightarrow$ No TSP $\longrightarrow$ - With TSP

(b) $\mathrm{v} / \mathrm{c}$ Ratio $=0.9$

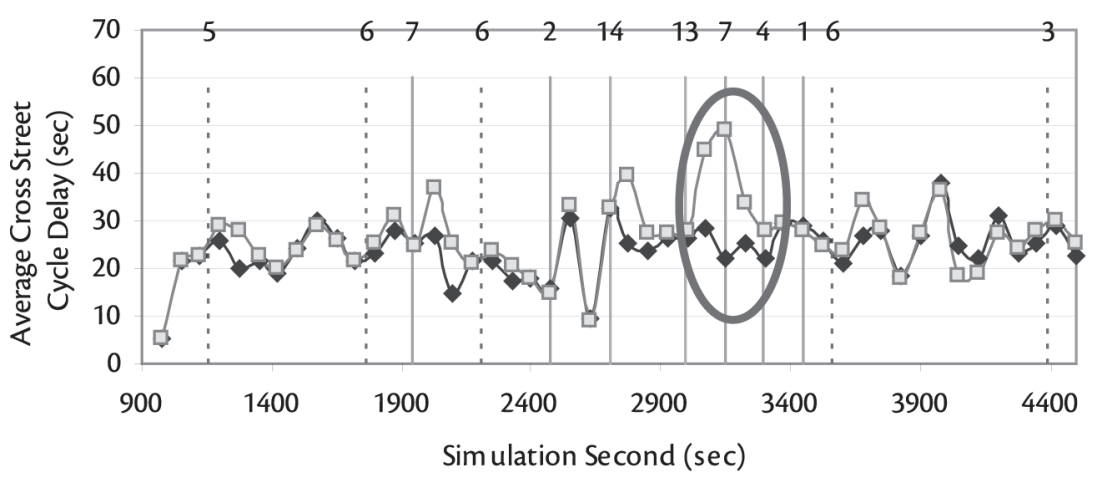

$\multimap$ No TSP $\square-$ With TSP 
(c) $\mathrm{v} / \mathrm{c}$ Ratio $=\mathbf{1 . 0}$

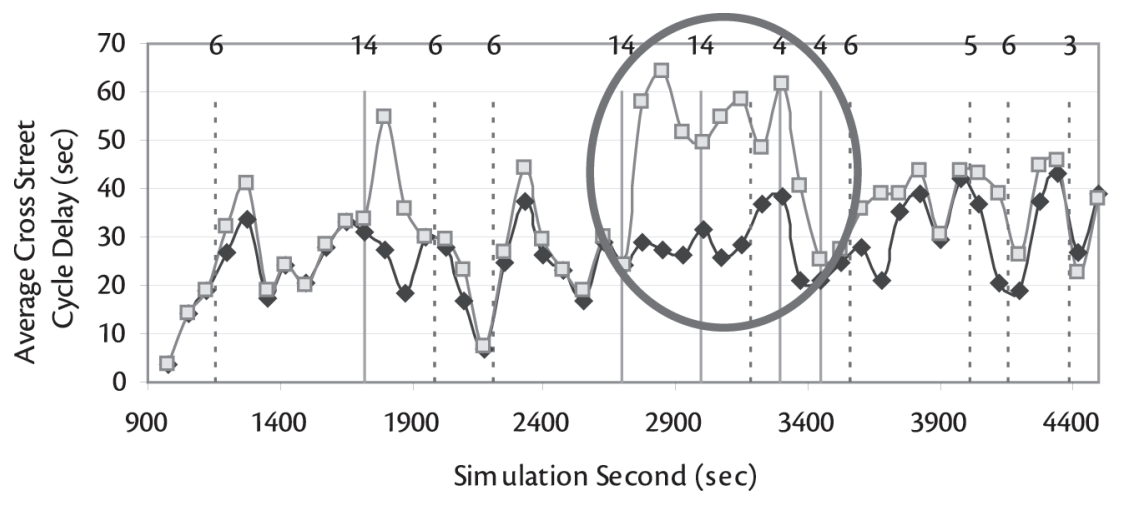

$\longrightarrow$ No TSP $\longrightarrow$ - With TSP

Figure 3. Bus Headway Impact (with TSP)

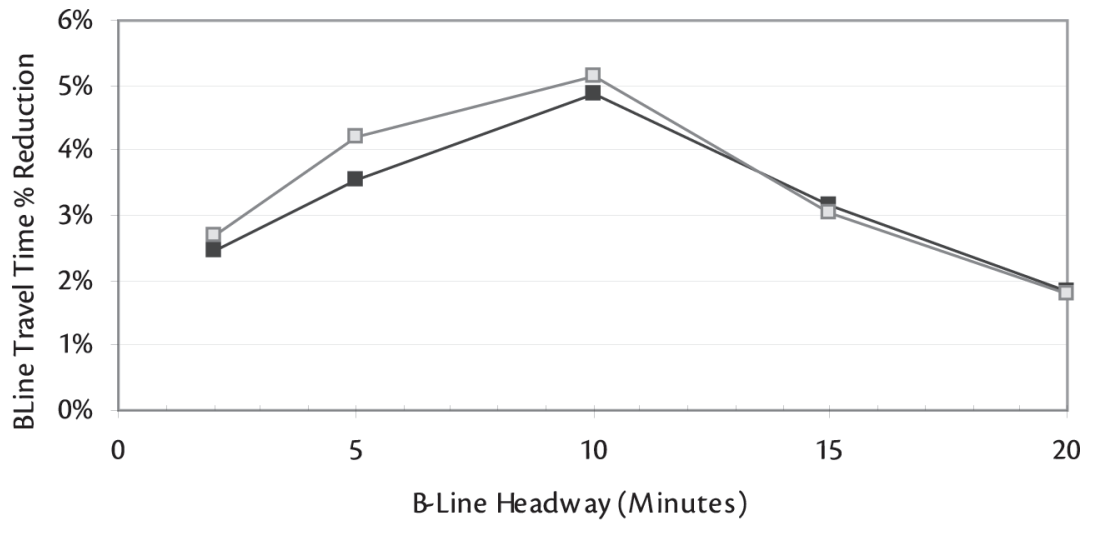

$\longrightarrow$ No Successive TSP $\quad \square-$ Successive TSP 
bus travel time is reduced, because a higher bus volume increases delay of the buses.

Results also show that allowance of TSP calls in successive cycles would bring a higher improvement in bus travel time at smaller headways, at which a higher number of TSP calls would be triggered in successive cycles. However, at B-Line bus headway of 2 minutes, the improvement decreases, because a higher bus volume would increase B-Line bus delay in the network.

\section{Bus Stop Location (Approach-Level)}

For this experiment, an "isolated-intersection model" is used because the B-Line bus performance on an approach is studied. The model assumes a 4-minute bus headway, allowance of TSP calls in successive cycles, and provision of TSP only to the northbound B-Line buses. Two bus stop scenarios are considered in this experiment:

- Farside Bus Stop Scenario: Stops are placed on the farside (or downstream) of a signalized intersection.

- Nearside Bus Stop Scenario: Stops are placed on the nearside (or upstream) of a signalized intersection.

The above bus stop location scenarios are examined under various Granville Street traffic volumes: 500, 1000, 1500, 2000, and $2500 \mathrm{Veh} / \mathrm{hr} / 3$-lanes, representing $\mathrm{v} / \mathrm{C}$ ratios from 0.2 to 0.95 . Figure 4 shows the comparison. The $\mathrm{B}$-Line bus delay value expresses only the traffic delay of the buses, i.e., bus dwell time delay has been excluded.

Figure 4 illustrates that a nearside bus stop would cause a higher delay to the BLine buses than a farside bus stop. This is because a significant portion of the green extension would be wasted while passengers board and alight at a nearside bus stop, thereby lowering the green extension success rate of the buses. This lengthens the bus waiting times at a signal and causes higher delays to the B-Line buses. This result is in agreement with the findings of Daniel (1997) and Huffman, et al. (1998) that a farside bus stop is more preferred when TSP is implemented. However, it should be noted that it is possible to address some of the nearside bus stop conditions for the implementation of TSP, such as placing the detector immediately downstream of the stop or using delay timers if dwell time at a bus stop is consistent. 


\section{Figure 4. Bus Stop Location Impact on Average Bus Delay (with TSP)}

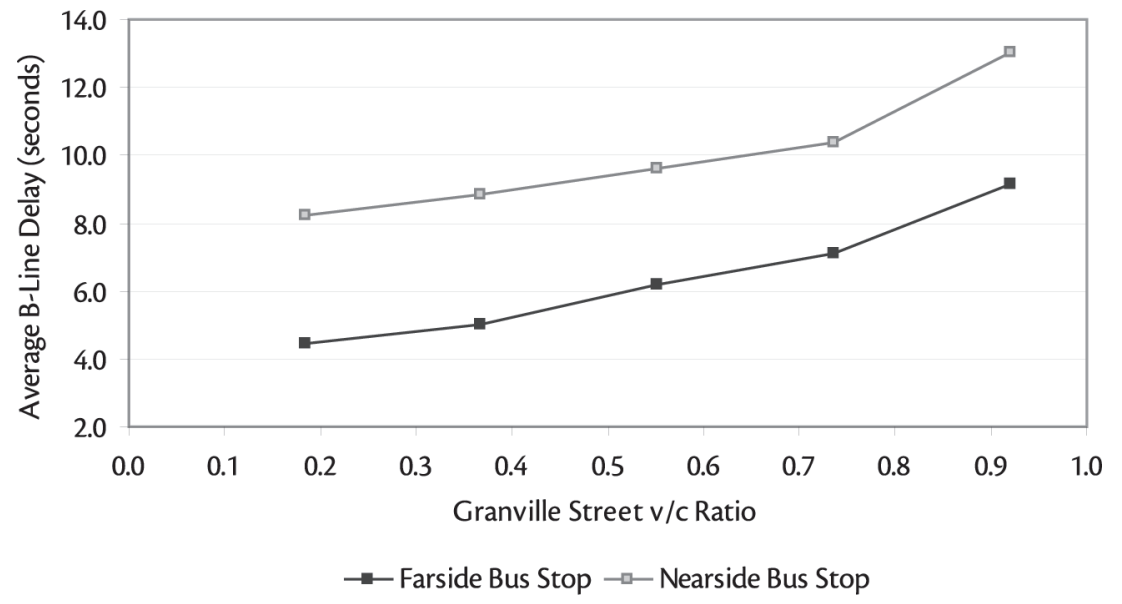

Figure 5 shows the percentage increase in the average B-Line bus delay under different Granville Street (or bus approach) v/c ratios when a bus stop is moved from the farside to the nearside of an intersection. In general, the bus delay would increase when a farside bus stop is converted to a nearside bus stop, and the deterioration in the bus delay would reduce as the bus approach $v / c$ ratio increases. This is likely due to a higher influence on bus delay by traffic congestion than by bus stop location, when the bus approach $\mathrm{v} / \mathrm{c}$ ratio increases. 


\section{Figure 5. Nearside Bus Stop Impact on TSP Effectiveness}

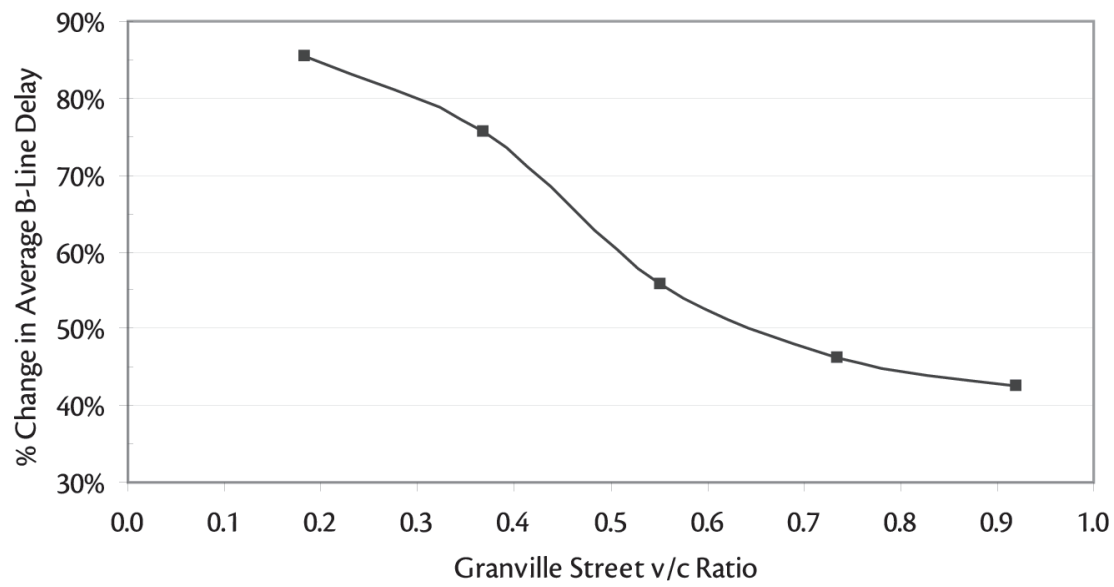

\section{Bus Detector Location (Approach-Level)}

An "isolated-intersection model" is deployed for this experiment because only the B-Line bus approach delay is examined. For this experiment, seven B-Line bus checkin detector location scenarios are analyzed for a farside and a nearside bus stop, when TSP is implemented. Figure 6 shows the comparison. The bus delay value only expresses the traffic delay of the buses, i.e., dwell time delay has been excluded.

As discussed earlier, a farside bus stop would give a lower bus delay than a nearside bus stop. Additionally, the result shows that the bus delay is less sensitive to the check-in detector location when a nearside bus stop is placed. This is because the performance of the B-Line buses would be more influenced by dwell time at nearside bus stops than by the location at which the buses are detected. When a farside bus stop is used, the improvement of TSP on bus delay would increase when check-in detectors are placed further from the intersection stop bar. This is because placing the detector further from the intersection would allow the red truncation or green extension to start earlier. However, the check-in detector cannot be placed too far from the intersection because of greater uncertainty in bus travel time from the check-in detector to the intersection. It should also be noted that the optimal detector location might vary with different signal conditions (e.g., cycle length, maximum and minimum green times) and bus arrival pattern. 


\section{Figure 6. Comparison of Detector Location Impact on Average Bus Delay for Farside and Nearside Bus Stops (with TSP)}

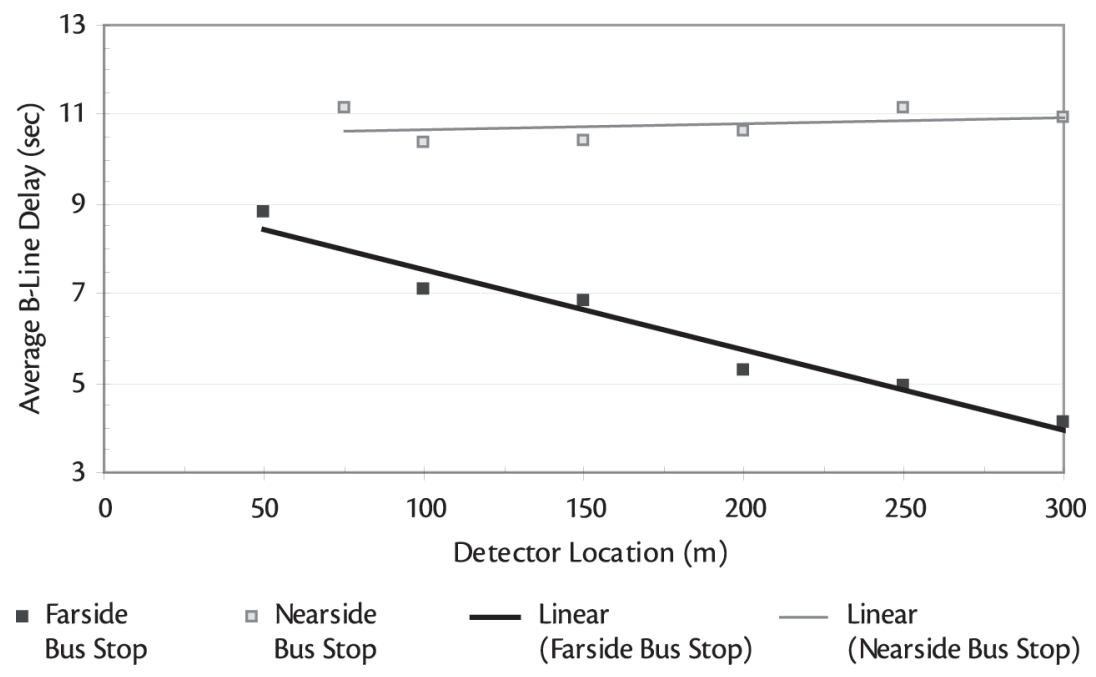

Table 1 compares the number of green extensions calls granted, the number of green extension failures (i.e., the number of B-Line buses that cannot check-out after the maximum green time elapsed), and the green extension success rates for various bus stop location and bus detector location scenarios. Results show that a higher number of green extensions are called when a nearside bus stop is used or when the check-in detectors are placed further from an intersection. Under these conditions, the B-Line buses require more time to enter the intersection after checking in; therefore, more B-Line buses would require a green extension to clear the intersection. In addition, the green extension success rate would decrease as the bus detector is placed further from the intersection, because this lengthens the time required for the bus to enter an intersection after checking in. 


\section{Table 1. Green Extension (GE) Effectiveness for Farside and Nearside Bus Stops}

\begin{tabular}{|l|c|c|c|c|c|c|}
\hline \multirow{2}{*}{ Detector Location } & \multicolumn{2}{|l|}{ Total \# of GE } & \multicolumn{2}{l|}{ \# of GE Failure } & \multicolumn{2}{l|}{ GE Success Rate } \\
\cline { 2 - 7 } & Farside & Nearside & Farside & Nearside & Farside & Nearside \\
\hline $50 / 75 \mathrm{~m}$ & 2 & 6 & 0 & 2 & $100 \%$ & $61 \%$ \\
$100 \mathrm{~m}$ & 3 & 6 & 0 & 2 & $100 \%$ & $61 \%$ \\
$150 \mathrm{~m}$ & 3 & 6 & 0 & 2 & $100 \%$ & $61 \%$ \\
$200 \mathrm{~m}$ & 4 & 7 & 0 & 3 & $100 \%$ & $52 \%$ \\
$250 \mathrm{~m}$ & 6 & 9 & 2 & 6 & $71 \%$ & $37 \%$ \\
$300 \mathrm{~m}$ & 6 & 9 & 2 & 6 & $71 \%$ & $37 \%$ \\
\hline
\end{tabular}

\section{Left Turn Volume/ Lane/ Phase (Approach-Level)}

The "isolated-intersection model" is used for this experiment. Effects of the leftturn traffic (in direction parallel to the through-traveling buses) on TSP effectiveness of through-traveling buses at a signalized intersection are studied. The opposing-through $\mathrm{v} / \mathrm{c}$ ratio is set to different values to generate different dissipation conditions for left-turn traffic. The influence of left-turn volume on TSP effectiveness is compared under three left-turn conditions:

i. Shared through-left-turn (TH-LT) lane with permissive left-turn phase

ii. Exclusive left-turn (LT) lane with permissive left-turn phase

iii. Exclusive left-turn (LT) lane with protected-permissive left-turn phase.

In this analysis, the scenario of no left-turn traffic is used as the benchmark condition because this scenario is expected to give the highest effectiveness of TSP. The TSP effectiveness of each left-turn scenario is measured by the change in bus approach delay relative to this benchmark left-turn volume (i.e., no left-turn).

The B-Line bus approach delay is examined under the three aforementioned leftturn conditions for left-turn (LT) volumes (in direction parallel to the throughtraveling buses) of 25, 50, 100, 150, and $200 \mathrm{Veh} / \mathrm{hr}$ and opposing-through (Opp$\mathrm{TH}$ ) volume of 1,000 Veh/hr, 1,500 Veh/hr and 2,000 Veh/hr, representing $\mathrm{v} / \mathrm{c} \mathrm{ra-}$ tios of $0.37,0.55$ and 0.74 , respectively. It should be noted that high left-turn volume and high opposing-through volume scenarios might not be realistic for a permissive left-turn phasing scheme, but are performed to illustrate the theoretical 
trend of the change in B-Line bus delay and to compare results with other left-turn conditions.

Table 2 shows a comparison of bus approach delay results for various left-turn conditions, when TSP is implemented. The result shows that, without the use of a

\section{Table 2. Left Turn Traffic Impact on Bus Average Approach Delay (with TSP)}

\begin{tabular}{|c|c|c|c|c|}
\hline \multirow{2}{*}{$\begin{array}{l}\text { Opp-TH } \\
\text { Vol }\end{array}$} & \multirow{2}{*}{$\begin{array}{l}\text { LT } \\
\text { Vol }\end{array}$} & \multicolumn{3}{|c|}{ Change in Average B-Line Bus Approach Delay (Seconds) } \\
\hline & & $\begin{array}{l}\text { Permissive LT Phase, } \\
\text { Shared LT-TH Lane }\end{array}$ & $\begin{array}{l}\text { Permissive LT Phase, } \\
\text { Exclusive LT Lane }\end{array}$ & $\begin{array}{l}\text { Protected LT Phase, } \\
\text { Exclusive LT Lane }\end{array}$ \\
\hline \multirow{6}{*}{$\begin{array}{l}1,000 \\
v / c=0.37\end{array}$} & 0 & 0.0 & 0.0 & 0.0 \\
\hline & 25 & 0.5 & -0.3 & -0.1 \\
\hline & 50 & 0.9 & -0.4 & -0.2 \\
\hline & 100 & 3.0 & 0.0 & -0.4 \\
\hline & 150 & 7.2 & 0.6 & 0.0 \\
\hline & 200 & 32.3 & 2.0 & 0.4 \\
\hline \multirow{6}{*}{$\begin{array}{l}1,500 \\
v / c=0.55\end{array}$} & 0 & 0.0 & 0.0 & 0.0 \\
\hline & 25 & 1.2 & -0.1 & -0.4 \\
\hline & 50 & 2.2 & -0.2 & 0.1 \\
\hline & 100 & 25.2 & 2.3 & -0.1 \\
\hline & 150 & 63.2 & 22.2 & -0.1 \\
\hline & 200 & 83.9 & 49.8 & -0.1 \\
\hline \multirow{6}{*}{$\begin{array}{l}2,000 \\
v / c=0.74\end{array}$} & 0 & 0.0 & 0.0 & 0.0 \\
\hline & 25 & 1.2 & 0.0 & 0.2 \\
\hline & 50 & 5.6 & 0.2 & 0.1 \\
\hline & 100 & 54.4 & 11.1 & 0.0 \\
\hline & 150 & 90.3 & 42.9 & 0.5 \\
\hline & 200 & 103.2 & 58.7 & 0.0 \\
\hline
\end{tabular}

Note:

- All changes are compared to the "No Left-Turn" scenario for their corresponding opposingthrough volume and left turn condition.

- Bolded values represent scenarios that cause significant increase in B-Line bus approach delay.

- Italic values represent results that might have caused by some fluctuation in the VISSIM simulation from one scenario to another. The changes are assumed negligible when the absolute change is less than 1.0 second. 
left-turn lane or a protected left-turn phase, a high left-turn volume would significantly increase the average delay of the buses when TSP is implemented. A high left-turn volume and queue would increase the traffic usage on the center and rightmost lanes, thereby increasing traffic hindrances to B-Line buses that run on the rightmost lane. Additionally, the $\mathrm{v} / \mathrm{c}$ ratio of opposing-through volume would also significantly impact bus delay because the dissipation of left-turn traffic is controlled by the availability of an adequate gap of the opposing-through traffic. The result also demonstrates a need for a protected left-turn phase and an exclusive left-turn lane at an intersection with high left-turn and opposing-through volumes, in order to maintain the effectiveness of a TSP application.

\section{Signal Coordination (Corridor-Level)}

This experiment tests the signal coordination impact on the effectiveness of TSP. Default parameters and the NoTAC model are deployed to evaluate the Granville Street corridor performance. Two coordination scenarios are compared:

- Granville Street with Signal Coordination: To maintain coordination, the green time of the cross street approaches is shortened accordingly when a TSP call (i.e., green extension or red truncation) is granted. In addition, TSP calls are not responded for two successive cycles to reduce the adverse effect on cross street traffic.

- Granville Street without Signal Coordination: No signal coordination is maintained along the Granville Street corridor (NTCIP 1211 standard violated). The cycle length at an intersection could fluctuate with the length of a green extension or red truncation; and the length of the cross street green time could be maintained after a green extension is conferred. For this scenario, TSP calls do not respond for successive cycles, because the cross street green time is not shortened after a TSP call.

The TSP effectiveness is expressed as the change in traffic delay in the "with coordination" scenario, the benchmark condition. The evaluations are performed at a corridor-level and are disaggregated by the following categories: the entire corridor (i.e., major and cross streets traffic combined), major traffic approaches, cross street approaches, and individual major traffic approach. Table 3 shows that removing signal coordination from Granville Street would increase the entire corridor delay, which is attributed to an increase in the major traffic delay on Granville Street. Meanwhile, removing the coordination would result in minimal improvement in the cross street total delay, because green time for the cross street approaches is allowed to be maintained after a TSP call. These results suggest that, for 
the objective of maximizing TSP improvement in the total delay of the entire corridor, TSP would be more effective when applied with signal coordination. This result agrees with Daniel's (1997) proposal that providing priority for transit vehicles in a non-coordinated network would increase the overall delay of vehicles in the network.

Table 3. Signal Coordination Impact on TSP Effectiveness

\begin{tabular}{|l|l|l|l|l|}
\hline Total Delay (Seconds) & $\begin{array}{l}\text { Delay with } \\
\text { coordination * }\end{array}$ & $\begin{array}{l}\text { Delay with No } \\
\text { Coordination * }\end{array}$ & $\begin{array}{l}\text { Delay } \\
\text { Change ** }\end{array}$ & $\begin{array}{l}\text { Delay } \\
\text { Change (\%) ** }\end{array}$ \\
\hline Entire Corridor & 8458 & 8607 & +149 & $+2 \%$ \\
\hline Major traffic (vehicle) & 6216 & 6341 & +125 & $+2 \%$ \\
\hline Cross Street traffic & 2260 & 2250 & -10 & $-0 \%$ \\
\hline Northbound Only & \multicolumn{5}{|l}{} \\
\hline Northbound B-Line Buses & 209 & 223 & 14 & $6 \%$ \\
\hline Northbound All Traffic & 3820 & 4460 & 640 & $17 \%$ \\
\hline Southbound Only & \multicolumn{5}{|l}{} \\
\hline Southbound B-Line Buses & 299 & 299 & -0 & $0 \%$ \\
\hline Southbound All Traffic & 2396 & 1899 & -497 & $-21 \%$ \\
\hline
\end{tabular}

* The delay values are of scenarios with the implementation of TSP.

** The change or percentage change in delay is with respect to the "with coordination" scenario, which is the actual scenario on the Granville Street corridor.

The result also shows that removing signal coordination from Granville Street would worsen the delay of the northbound general traffic and the northbound B-Line buses, which the default signal coordination heavily favors. On the other hand, removing coordination along Granville Street is observed to bring about minimal improvement to the southbound B-Line buses and significant improvement to the southbound general traffic, which the original signal coordination does not favor.

It should be noted that during the period studied (i.e., AM peak), northbound volume was almost double the southbound volume. Therefore, it would not be acceptable to deteriorate northbound traffic performance for the benefit of southbound traffic. As a result, coordination should be maintained with TSP application for the benefit of the majority of traffic on Granville Street. 


\section{Conclusion}

Based on the results of the analyses in this research, the following general recommendations can be made:

1. TSP application would be most effective under moderate-to-heavy bus approach traffic condition.

2. The allowance of TSP should be carefully considered at cross street with high $\mathrm{v} / \mathrm{c}$ ratio.

3. Left-turn volume (in the direction parallel to the through-traveling TSPeligible buses) and its associated queue could impact the effectiveness of TSP. For the highest effectiveness of TSP, exclusive left-turn lane and protected left-turn phase for the left-turn traffic should be considered when applying TSP at signalized intersection with heavy left-turn and opposingthrough volumes.

4. TSP is more sensitive to the location of check-in detectors when a farside bus stop is placed than when a nearside bus stop is placed.

5. Placing the bus check-in detector further from the intersection to a certain limit (i.e., within the clearance distance for the maximum green extension interval) could improve B-Line bus performance and maintain the effectiveness of green extension.

6. For the best performance of the entire corridor, coordination should be maintained when implementing TSP.

Based on the results of the analyses in this research, the following recommendations are specific to the TSP application of the 98 B-Line buses on Granville Street:

1. TSP application would be most effective at Granville Street v/c ratios between 0.6 and 0.9 .

2. 10 minutes would be the optimal bus headway that brings about the highest effectiveness of TSP in improving the bus travel times.

3. TSP could have significant adverse impacts on cross street traffic at cross street $\mathrm{v} / \mathrm{c}$ ratios above 0.9 . 


\section{Acknowledgements}

This research was funded by the National Sciences and Engineering Research Council of Canada (NSERC) and the Department of Civil Engineering at the University of British Columbia. Much of the data of this research were obtained from the City of Vancouver and IBI Group. 


\section{References}

Agrawal, B. B., S. T. Waller, and A. Ziliaskopoulos. 2002. A modeling approach for transit signal preemption. Paper presented at the 81st Annual Meeting of the Transportation Research Board.

Balke, K. N., C. L. Dudek, and T. Urbanik, II. 2000. Development and evaluation of intelligent bus priority concept. Transportation Research Record 1727: 12-19.

Chatila, H. F., and M. J. Swenson. 2001. Transit signal priority along State Route 522. Paper presented at the ITE Quad Conference, Vancouver, B.C..

Daniel, J. 1997. Bus signal priority along congested corridors. Proceedings of the ASCE conference on Traffic Congestion and Traffic Safety in the $21^{\text {st }}$ Century.

Duerr, P. A. 2000. Dynamic right-of-way for transit vehicles: An integrated modeling approach for optimizing signal control on mixed traffic arterials. Paper presented at the $79^{\text {th }}$ Annual Meeting of the Transportation Research Board.

Garrow, M., and R. Machemehl. 1998. Development and evaluation of transit signal priority strategies. Paper presented at the $77^{\text {th }}$ Annual Meeting of the Transportation Research Board.

Huffman, B., J. Paquet, J. Weesner, and M. Pitstick. 1998. Signal priority demonstration in suburban Chicago. Proceedings of the APTA 1998 Bus Operations, Technology and Management Conference.

Khasnabis, S., and R. K. Rudraraju. 1997. Optimum bus headway for preemption: A simulation approach. Transportation Research Record 1603: 128-136.

PTV Simulation - VISSIM. 2002. www.english.ptv.de/cgi-bin/produkte/vissim.pl

Skabardonis, A. 2000. Control strategies for transit priority. Paper presented at the $79^{\text {th }}$ Annual Meeting of the Transportation Research Board.

\section{About the Authors}

Vıккı NGan (vikki@telus.net) is a junior transportation engineer at the Vancouver office of IBI Group. She obtained her B.A.Sc. in civil engineering and a M.A.Sc. from the University of British Columbia. Ms. Ngan has particular interest in intelligent transportation systems, rapid transit, and transit priority systems. 
TARek SAYed (tsayed@civil.ubc.ca) is a professor in the department of civil engineering at the University of British Columbia. He otained his B.Sc. in civil engineering from Ain Shams University in Egypt, and his M.A.Sc. and Ph.D. from the University of Brisith Columbia. He teaches graduate and ndergraduate courses in traffic engineering and safety. Dr. Sayed's research interests include several areas in transportation engineering, traffic operations and safety, intelligent transportation systems, and economic analysis of transportation projects. He was recently appointed as a distinguished university scholar.

Akmal Abdelfatah (akmal@aus.ac.ae) is an assistant professor in the school of engineering at the American University of Sharjah in the United Arab Emirates. 